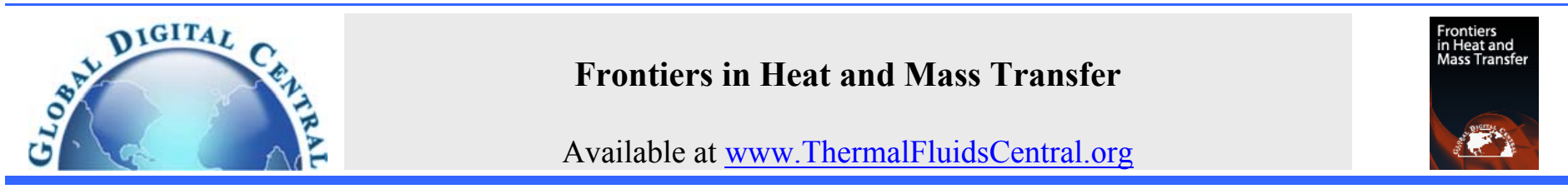

\title{
FOULING PHENOMENON AND ITS EFFECT ON HEAT EXCHANGER: A REVIEW
}

\author{
Stephen K. Ogbonnaya, Oluseyi O. Ajayi * \\ Mechanical Engineering Department, Covenant University, Ota, P.M.B. 1023, Ota, Ogun State, Nigeria
}

\begin{abstract}
Heat exchangers as a heat transfer device has gained wide applications across different levels of domestic and industrial set-ups. Various studies have been carried out to study, analyse and predict its performance. However, one major phenomenon that limits heat exchanger performance is attributed to fouling. Based on this, various studies and approaches have focused on reduction, elimination and mitigation of fouling. This study therefore focused on this. It reviewed several attempts that have been carried out to understand and mitigate the incidents of fouling in heat exchangers. The study found that despite the existing models developed towards understanding fouling, there is no single model that has provided an accurate prediction of fouling in all the different types of heat exchangers. Also, majority of existing results have limited applications and some of the solutions are only peculiar to particular type of heat exchanger. Further to this, majority of the study results only pointed to small scale laboratory test schemes and there is absence of in-situ measurements that predicts actual (real life) service performance.
\end{abstract}

Keywords: Fouling model, Heat Transfer, Energy System, Heat Exchanger.

\section{INTRODUCTION}

Heat exchangers are devices used in both industrial and domestic applications that involve energy (heat) transfer fluids. Generally, heat exchangers are classified as counter-flow, cross-flow and parallel flow with their operating conditions categorized as steady state operation and dynamic operation (Gudmundsson et al., 2011). In steady state operations, the mass flow and temperatures do not change with time like they will do in dynamic operations (Yunus and Afshin, 2015). Often there is accumulation of deposits on the heat transfer surfaces of heat exchangers while in service. As the deposits accumulate leading to increased fouling, the efficiency of the heat exchanger reduces, making it important to understand the condition of the heat exchanger while in use. The accumulation of these unwanted material on the heat exchanger surface in such a way that it affects its heat transfer efficiency is called fouling. Based on the prevalence of fouling and its attendant challenges in heat exchangers, modern heat exchangers are generally designed to tolerate slight fouling (Gudmundsson et al., 2011). Moreover, there are different types of fouling mechanisms that can either occur individually or simultaneously. The most common as described by Epstein (1999) are the Scaling/Precipitation, Particulate/Sedimentation, Corrosion, Chemical, Freezing and Biological fouling.

Scaling fouling otherwise known as precipitation or crystalline fouling is the commonest type of fouling and is often as a result of reverse solubility salts like calcium carbonate $\left(\mathrm{CaCO}_{3}\right)$ typically found in water. The solubility of these salts decline as the temperature increases and hence form deposits on the surface of the heat exchanger. It is difficult to remove scale fouling via mechanical means, and as a result, the use of chemical cleaning methods may be required. Particulate fouling on the other hand, is the accumulation of particles, on a heat transfer surface, that forms an insulating layer, and reduces the rate of heat transfer leading to operations failure (Abd-Elhady et al., 2007). When certain particles like sand, dirt or rust in the fluid settle and accumulate on the surface of the heat transfer equipment, sedimentation occurs. As noted in scale fouling, the intricacy of the heat exchanger design and their nature may make mechanical removal of the deposits to be very tough. Corrosion fouling results from a chemical reaction involving the surface material of the heat exchanger. Metals such as copper and aluminum form adherent oxide coatings which serve to passivate the surface and preclude additional corrosion. According to Epstein (1999), relatively thin coatings of metal oxides which are products of corrosion with low thermal conductivity may significantly affect heat exchanger performance.

In addition to the aforementioned, chemical fouling comes from chemical reactions in the fluid stream. It results in the deposition of materials on the heat exchanger surface. This type of fouling is common for chemically sensitive materials when the fluid is heated to temperatures near its decomposition (degradation) temperature (Epstein, 1999; Kazi et al. (2009). Coking of hydrocarbon material on the heat transfer surface is also a common chemical fouling problem. Whereas, freezing fouling occurs when a portion of the hot stream is cooled to near the freezing point of one of its components, biological fouling occurs when biological organisms grow on heat transfer surfaces (Kazi et al., 2009). The biological organisms include algae and other microbes such as barnacles and zebra mussels. One major issue about fouling is the fact that it has a chronic operational effect that is considered the major unsolved problem in heat transfer technology (Costa et al., 2011).

Fouling rate, defined as the difference between the material deposition and removal rates on the heat transfer surfaces (Morimoto et al., 2011), is an important phenomenon that has capacity to determine the performance of a heat exchanger. As deposits accumulate on the heat transfer area, the resistance to heat transfer increases and the effectiveness of the heat exchanger diminishes. The cost of fouling is connected to energy wastage and associated downtime cost implication. This invariably is due to the period of heat exchanger cleaning and additionally due to reduced product quality. There are many ways to detect fouling. However, many of the classical methods require the

\footnotetext{
*Correspondence: oluseyi.ajayi@,covenantuniversity.edu.ng
} 
process to be operating in a steady state condition or to be stopped (Gudmundsson et al., 2011). The removal rate varies directly with the shear stress and the deposit thickness. Heat exchangers for use in preheat trains of crude oil refineries currently appear to be designed on the basis of pre-specified fouling factors (Polley et al., 2009). However, the validity of fouling factors has been the focus of concerns since the early 1990's (Crittenden et al., 2007).

\section{FORMATION OF FOULING}

Fouling in heat exchangers occurs over a period of time while the equipment is in service. Hence, Kazi et al. (2009) proposed five steps that lead to the gradual development of deposits namely generation, transportation, attachment, removal, and aging. Abd-Elhady et al. (2009) investigated the influence of flow direction with respect to gravity on particulate fouling of heat exchangers experimentally to determine the optimal flow direction in order to minimize fouling. It was observed that fouling starts at the point of stagnation irrespective of the flow direction, and at the top of the heat exchanger tubes. The particulate fouling therefore grows from these two points until it connects and the fouling layer covers the whole surface of the heat exchanger tube. Mixtures of some crude oils in specific proportions have also been known to cause significant fouling in refinery preheat trains, usually due to precipitation of asphaltene (Saleh et al., 2005). Four crude oils used in Australia (Bach Ho, Gippsland, Cossack and Kutubu) were involved in the study. It concluded that fouling rates of individual oils decreased with decreasing asphaltene, suspended solid content, decreased colloidal instability index and increasing solubility blending number. The importance of particulate fouling was further proven by significant decrease in the amount of suspended solids over each run. The fouling rate was linearly related to the magnitude of this decrease. However, for oils and their mixtures, the initial fouling rate could be correlated with the colloidal instability index (CII) or with more scatter, to the concentration of insoluble solids as shown in the Eq. (1):

$$
\frac{\mathrm{dR}_{\mathrm{f}}}{\mathrm{dt}}=\mathrm{a}(\mathrm{CII})^{\mathrm{n}}
$$

where the constant, $a=2.17 \times 10^{-09} \mathrm{~m}^{2} \mathrm{~K} / \mathrm{kJ}$, and the exponent on the colloidal instability index $(\mathrm{CII}), \mathrm{n}=3.2$. The parameter, $\mathrm{a}$, is the fouling rate at $\mathrm{CII}=1$.

In the same vein, Lane and Harris (2015) examined the effect of mixing different crude oil on the fouling data before the fluid is loaded into the test apparatus. To ensure consistent mixing of the crude, the study used a drum tumbler acquired by HTRI set to a maximum speed of $20 \mathrm{rpm}$, tilted at a 45-degree angle and mixed for 15 minutes. The study concluded that fouling rates, resistances and deposits varied based on how the mixing was conducted while varying Nusselt number between runs can be an indicator of inadequate mixing. Various studies have investigated other factors that contribute to the formation of fouling in a heat exchanger. According to Barrie et al. (2011), the rate of fouling often exhibits a strong dependence on temperature, which in this case is normally characterized in terms of activation energy, $E_{a c t}$, via the Arrhenius Eq. (Eq. (2)):

$$
\text { Rate }=A \exp \left(-\frac{\text { Eact }}{\mathrm{RT}}\right)
$$

where: $\mathrm{R}$ is the gas constant; $\mathrm{A}$ is the Arrhenius pre-factor and $\mathrm{T}$ is the absolute temperature.

Further to this, the study found that fouling rates can be subjected to factors such as flow rate, with the flow influenced by the compensation effect. Furthermore, it discussed the conditions under which the compensation effect is expected when flow rate is varied using synthetic data generated by a model for fouling. It was concluded that the mathematical reason that account for the observation of the compensation effect (EC) in heat exchanger fouling data are statistical compensation effect. This is due to random errors in the kinetic measurements on different crude oils at otherwise identical conditions. Also, another reason was due to the analysis of the overall rate of fouling by the Arrhenius equation rather than an intrinsic rate constant. Crittenden et al. (2007) studied fouling of Maya crude and the study reveals a seeming straightforward dependence of initial fouling rate on surface temperature. A maximum was found in the initial fouling ratevelocity relationship similar to a modelled chemical system of styrene polymerization. The apparent activation energy for the crude oil ranged from $26.4 \mathrm{~kJ} / \mathrm{mol}$ at $1.0 \mathrm{~m} / \mathrm{s}$ to $245 \mathrm{~kJ} / \mathrm{mol}$ at $4.0 \mathrm{~m} / \mathrm{s}$. Surface temperatures at which the fouling rate became velocity-independent were $274^{\circ} \mathrm{C}$ and $77^{\circ} \mathrm{C}$ for Maya crude oil and styrene, respectively. For surface temperatures more than this isokinetic temperature, an increase in velocity would lead to an increase in the rate of fouling. The opposite velocity effect arises for surface temperatures lower than the isokinetic temperature. The concept of an isokinetic point in crude oil fouling was proposed by Bennett et al. (2007). It found that the Arrhenius plots for four crude oils all crossed at about the same temperature. At this temperature, the fouling rates for the four crude oils were the same. The work developed the isokinetic concept to take on a different meaning for the case of fouling in a single chemical system (Maya crude oil or styrene polymerization) rather than for a cluster of similar fluids. The study calculated fouling rates from the formula recommended in Crittenden et al. (1987a) and Bennett et al. (2007) as:

$$
R_{f}-\left(\frac{T_{s}-T_{b}}{q}\right)_{t}-\left(\frac{T_{s}-T_{b}}{q}\right)
$$

where, $q$ is the heat flux and $T_{s}$ and $T_{b}$ are the local surface and bulk temperatures at time $t$ and time zero, respectively.

Eq. (3) avoids the need to calculate film heat transfer coefficients and all the errors associated with estimating their parameters. At constant bulk temperature and constant heat flux, the Eq. (3) above becomes:

$$
\mathrm{R}_{\mathrm{f}}=\left(\frac{\mathrm{T}_{\mathrm{st}}-\mathrm{T}_{\mathrm{so}}}{\mathrm{q}}\right)
$$

where, $T_{s t}$ and $T_{s o}$ are the surface temperatures at time $t$ and zero, respectively.

Srinivasan and Watkinson (2003 and 2006) also carried out a thermal fouling study using three sour Canadian crude oils. Experiments were carried out in a recirculation fouling loop, equipped with an annular electrically heated probe. Fluids at pressures of about $1000 \mathrm{kPa}$ to 1340 $\mathrm{kPa}$ under a nitrogen atmosphere were re-circulated at a velocity of 0.75 $\mathrm{m} / \mathrm{s}$ for periods of 48 hours, and the decline in heat transfer coefficient followed under conditions of constant heat flux. The study demonstrated that fouling rate decreased slightly with increasing velocity but increased with both surface and bulk temperatures. Saleh et al. (2005) performed a study on the fouling characteristics of a light Australian Crude Oil. Like other results, the study showed that surface temperatures have a major impact on fouling rates. An increase of roughly $80^{\circ} \mathrm{C}$ results in tripling of the initial fouling rate. Fouling rates for this crude were in the range 2 to $6 \times 10^{-7} \mathrm{~m}^{2} \mathrm{~K} / \mathrm{kJ}$. The fouling rate increased by about $60 \%$ with increase in the bulk temperature from $80^{\circ} \mathrm{C}$ up to $120^{\circ} \mathrm{C}$. Fouling may be caused by asphaltene precipitation, oxidative polymerization and coke formation arising from components in the oil, while salts, sediments and corrosion products arise from impurities (Murphy and Campbell, 1992). Insoluble asphaltenes are considered to be a major cause of fouling in crude oil refining (Dickakian and Seay, 1988).

Yang et al. (2009) identified that a fouling process is often preceded by an induction period in which no significant fouling is observed. It developed a simple lumped parameter model (Eq. (5)) based on fractional surface coverage $\theta$ to correlate experimental data in the induction period.

$$
\theta=\left(\frac{1}{1+\mathrm{C} \mathrm{e}^{-\mathrm{kt}}}\right)
$$

The constant $\mathrm{k}$ is the lumped rate constant which may be assumed to depend on the surface temperature according to the Arrhenius Eq. given as: 


$$
\mathrm{K}=\mathrm{K}_{\mathrm{a}} \mathrm{e}^{-\mathrm{E}_{\mathrm{t}} / \mathrm{RT}}
$$

where $E_{i}$ is the activation energy for the induction/surface preconditioning phenomenon and $\mathrm{k}_{\mathrm{a}}$ is the pre-exponential factor. The model was tested on experimental data from crude oil fouling, calcium sulphate fouling and whey protein fouling. The study assumed that active foulant species stick to the surface and gradually cover it, the rate of change of surface coverage $\mathrm{d} \theta / \mathrm{dt}$ being proportional to the fractional free surface $(1-\theta)$. It was further assumed that the foulant already on the surface acts as a seed, attracting more foulant in a micro-growth manner such that the growth rate was proportional to $\theta$. The fouling layer grows on the covered surface and the fouling rate can be expressed as $\theta \mathrm{R}_{\mathrm{f}}{ }^{\prime}$ (where $\mathrm{R}_{\mathrm{f}}^{\prime}$ can be any established fouling rate expression). The model supports experimental observations in which shorter induction periods are found with higher surface temperatures.

In addition, Geddert et al. (2009) investigated the influence of several cleaning and fouling cycles on surface energy and the composition of the coatings. During the experimental investigation involving different cleaning methods from acid to base solution, it noted an influence of the interface reactions on the surface energy. Structural analysis of the Plasma Activated Chemical Vapour Deposition (PACVD) coatings have shown a build-in of oxygen inside the a-C:H matrix with time resulting in higher surface energies and an increase of polar interactions. The defects were noted to be acting as a starting point for crystallization fouling due to reduced activation energy of nucleation. This implies that they can enhance fouling, if the crystals are able to adhere to the coated surface, depending on the process conditions. Furthermore, to understand the rate of fouling in refinery heat exchangers, Ratel et al. (2013) presented the results of a novel fouling rig designed to mimic refinery conditions for different exchanger technologies. It examined shell and tube exchanger under various operating conditions where the results highlighted an increase in fouling rates with increasing temperature and decreasing shear. Accordingly, the test results demonstrated that under given conditions, cross flow plate exchanger fouled lesser than shell and tube exchanger. Moreover, Fu et al. (2017) studied the flow and heat transfer characteristics of a heat exchangers under the influence of ash deposition. A numerical model was employed for the study and found that particle deposition occurs mainly around the regions of stagnation and recirculation, and also separation and reattachment. It further reveal that the fouling deposition rate is inversely related to the flow velocity.

\section{EFFECT OF FOULING}

Fouling is one phenomenon that has significant adverse impacts on the efficiency and effectiveness of heat transfer equipment which includes economic loss, limitation in throughput and increased energy consumption. Due to increasing fuel cost and concerns about resource depletion and environment impact, energy efficiency has become a dominant aspect in most chemical, food-processing, and powergenerating processes. Hence, the proper design and the efficient performance of heat exchangers play an increasingly important role. The latter is frequently restricted by the process related formation of deposits on the heat transfer surfaces, which may lead to inefficient energy recovery, higher capital, operation and maintenance costs, safety and environmental hazards. Further to this, Demirskiy et al. (2018) posited that fouling on heat transfer surfaces negatively affects the heat exchanger performance and increase the associated energy consumption. This assertion highlights the very essence of fouling monitoring and detection. In addition, fouling may result in severely reduced throughput and loss of production during planned or unplanned plant shutdowns (Muller-Steinhagen et al., 2011). Fouling in heat exchangers is one of the major problems in chemical process industries, especially in refineries and considered as the main source for energy loss reaching up to $2 \%$ of the refinery total energy consumption (Akinc et al., 2013). It is well established that one of the major causes of refinery energy inefficiency is crude oil fouling in pre-heat trains. Therefore, heat integration and conservation are paramount (Macchietto et al., 2009). This position has been supported by Heins et al. (2007) who stated that in the refining industry the heat exchangers used for energy recovery suffer a progressive heat transfer efficiency loss due to fouling.

The contribution of fouling to the loss of profitability in petroleum industries is a major source of concern. The refining capacity loss due to preheat train fouling in one year was estimated at $25,400 \mathrm{~m}^{3} /$ day while the total cost of fouling in the refinery was estimated in 2003 to be $\$ 1.5$ million within a period of 3 months (Bories and Patureaux, 2003). Another $31,800 \mathrm{~m}^{3} /$ day capacity UK refinery reported in 2009 that $1^{\circ} \mathrm{C}$ loss of preheat temperature (that is oil temperature) cost the operator some $£ 250,000$ per annum (Macchietto et al., 2009). In addition, recent studies have shown that heat exchanger fouling may be responsible for $1 \%-2.5 \%$ of global $\mathrm{CO}_{2}$ emissions. $\mathrm{CO}_{2}$ emissions will result in environmental penalties. Considering that there are currently 750 refineries worldwide, the total amount of emitted $\mathrm{CO}_{2}$ due to fouling is approximately 88 million tons per annum (Müller-Steinhagen et al., 2009). Cost penalties due to fouling, such as additional fuel, down-time, overdesign and cleaning of chemicals, and so on, have been estimated at about $0.25 \%$ of the gross domestic product (GDP) of industrialized nations (Muller-Steinhagen et al., 2011).

The importance of energy conservation and management is glaring and is always a pursuit for small and large simple or complex process industries. However, fouling is one phenomenon that contends with this pursuit. This is because one of the major costs in petroleum processing is energy loss due to the build-up of thermal insulating foulant in preheat exchangers (Saleh et al., 2005). The mitigation of fouling in these units is of interest and was investigated to reduce the cost of lost energy (Polley et al., 2000). During operation, fouling reduces the thermal effectiveness of the preheat train. This phenomenon brings an increase in fuel burning in the furnaces, which generates significant economic losses (Costa et al., 2011). Ishiyama et al. (2007) studied the interaction between thermal and hydraulic effects which using engineering analyses and fouling rate laws based on the 'threshold fouling' concept. The study found a possible occurrence of a novel phenomenon called 'thermohydraulic channeling' under certain conditions in parallel heat exchangers. This phenomenon has deleterious impact on heat transfer in process equipment.

\section{PERFORMANCE MONITORING}

Monitoring the performance of heat transfer equipment as it relates to fouling will provide required triggers to take some proactive steps to ensure sustained efficiency and effectiveness of the units. Heins et al. (2007) presented a technique to monitor the performance of a network of heat exchangers and to optimize the cleaning plan. The procedure is centered on a complex simulation of the heat exchanger network using Hysys (from Aspen Technology). The simulation estimated service overall heat transfer coefficient with real operational data acquired from the unit's Plant Information System (PI). The study was done on a shell and tube heat exchanger using crude with specific crude properties. Akinc et al. (2013) carried out a study on fouling management, using heat exchanger simulation, data monitoring and fouling likelihood. The simulation was carried out based on the properties of fluid such as temperature, pressure and composition. The study monitored the fouling factor using the clean and service heat-transfer coefficients obtained from real-time data. The clean scenario simulation result was found to align with the post-cleaning period real-time data based on the software that was utilized in the simulation.

According to Joshi et al. (2007), the HEAT-For-Networks (HEAT4N) software has also been deployed in a research to monitor performance of heat exchangers. HEAT4N is a flowsheet based software tool that has been developed to monitor the fouling tendency and to assess the need for cleanout maintenance of individual heat exchangers within complex trains. The study reported that the applications of HEAT4N currently focus on petrochemical sites and in particular crude preheat trains, where optimal cleaning strategy is very dependent on determining how heat recovery can be manipulated on-the-run, in order to minimize the effects of fouling on the profitability of the running unit. 
However, it has been noted that the HEAT4N measures only the overall heat transfer coefficient and not the fouling resistance.

It is important that a fouling detection method can follow the process in real time, for it to become useful. The detection can be done for example by monitoring possible drift in parameters or variables in a model. Then the discrepancies between the model predictions and what is measured will indicate fouling. Gudmundsson et al. (2011) studied fouling detection in cross-flow heat exchangers under normal operating conditions using inlet and outlet temperatures and mass flow rates of the hot and cold fluids using both a physical method based on number of transfer unit relations and a black box model that is estimated using a clean heat exchanger. It concluded that both the physical method and black box model can detect fouling before a typical lower design limit of fouling was reached in dynamical conditions. However, it was noted that if slightly later detection time was acceptable, the physical method may be a better choice because of the information it gives on the overall heat transfer coefficient. In addition, there was the need to validate the model for parallel flow heat exchangers. Further work was carried out by Gudmundsson et al. (2013) where it tested two plate and frame heat exchangers in a research laboratory under fouling conditions. Three detection methods were compared namely the study of the evolution of the overall heat transfer coefficient, the evolution of the pressure drop, and the comparison of the experimental and estimated outlet temperatures. The study concluded that though the plate pattern might have significant influence on fouling, there is however no best fouling method among the ones utilized.

Fouling of heat transfer surfaces is a complex process which involves many parameters with poorly understood interaction. The ultimate deposit build-up, therefore, is the outcome of a sequence of various events on the surface, including competition between deposition and removal forces at micro- and macro-scales. All these would result in highly unstable processes with frequent significant fluctuations, based on the relationship between the heat transfer coefficient or fouling resistance and time (Al-Janabi et al., 2009). Hence, the study suggested that it is imperative to calculate the experiment uncertainty which involves both the bias and precision errors, based on two case studies for convective and pool boiling fouling experiments. The results show that the uncertainly was not constant and can vary up to a factor of 4 over the course of fouling run. The biggest uncertainty happened at the beginning of the fouling runs where the accumulations remain loose and hence the variability was significant. Thermal resistance $R_{f}$ and precipitation rate constant are very vital parameters for understanding fouling concept. Nevertheless, in a real process, it is challenging to determine those variables with high precision because there is no model to predict the phenomenon of fouling at acceptable level (Kaneko et al., 2009). Ingimundardóttir and Lalot (2011) carried out a study on heat exchanger fouling monitoring and explored the evolution of heat-exchanger efficiency. The study used a signal processing tool known as wavelet and concluded that the use of wavelets can lead to the discovery of heat exchanger fouling at initial stage. However, the study observed that independent of a sliding window; the technique can be computationally onerous if there is prolonged fouling. Labbadlia et al. (2017) on the other hand, carried out a computational fluid dynamics simulation to determine the effect of flow distribution on the performance of shell and tube heat exchangers. It demonstrated that a non-uniform flow distribution reduced the process efficiency and showed that the arrangement of the tubes has significant impact on the flow distribution. It concluded by showing that the $60^{\circ}$ arrangement gave $20 \%$ improvement on results compared to the conventional $90^{\circ}$, while the $45^{\circ}$ arrangement provided good uniformity of pressure distribution. However, due to the fact that the $45^{\circ}$ arrangement gave high velocity at maximum number of tubes, it became more suitable for high viscosity fluids while $60^{\circ}$ arrangement is most suitable for low viscosity fluids. More so, the $60^{\circ}$ arrangement possess reduced ability for fouling as a result of it ability to permit larger number of tubes.

Costa et al. (2011) proposed a procedure for the estimation of parameters used in crude fouling rates models via the development of a computational routine called HEATMODEL. The study focused on the obstacles associated with the search for the optimal set of parameters of the Ebert and Panchal models and its variants. It compared the performance of a conventional optimization algorithm (Simplex) with a more modern numerical technique (a hybrid Genetic Algorithm) using real data from a Brazilian refinery. The results indicated that, due to the complexity of the parameter estimation problem, the Simplex method may be trapped in poor local optima, thus indicating the importance of the utilization of global optimization techniques. Based on the findings, the computational routine can determine the values of the parameters of different fouling models available in literature and focusing on semiempirical models: Ebert and Panchal (1995), modified Ebert and Panchal (1995), Polley et al. (2002). and Nasr and Givi (2006). Table 1 provides a summary of the parameters obtained from previous models and the HEATMODEL.

Table 1: Model Parameter Values. Costa et al. (2011)

\begin{tabular}{|l|c|c|c|c|}
\hline Parameter & $\begin{array}{c}\boldsymbol{\alpha} \\
\left(\mathbf{m}^{\mathbf{2}} \mathbf{K} / \mathbf{J}\right)\end{array}$ & $\boldsymbol{\beta}$ & $\begin{array}{c}\text { Ea } \\
(\mathbf{K J} / \mathbf{M o l})\end{array}$ & $\begin{array}{c}\boldsymbol{\gamma}^{*} \\
\left(\mathbf{m}^{\mathbf{2}} \mathbf{K} / \mathbf{J} . \mathbf{P a}\right)\end{array}$ \\
\hline $\begin{array}{l}\text { Original Ebert }- \\
\text { Panchal (1995) }\end{array}$ & 8.39 & -0.88 & 68 & $4.03 \times 10^{-11}$ \\
\hline $\begin{array}{l}\text { Modified Ebert } \\
\text {-Panchal (1995) }\end{array}$ & 13.97 & - & 48 & $4.03 \times 10^{-8}$ \\
\hline $\begin{array}{l}\text { Polley et al. } \\
\text { (2002) }\end{array}$ & 277.8 & - & 48 & $4.17 \times 10^{-13}$ \\
\hline $\begin{array}{l}\text { Nars and Givi } \\
\text { (2006) }\end{array}$ & 0.011 & -1.547 & 22.618 & $2.67 \times 10^{-14}$ \\
\hline HEATMODEL & 127.7 & - & 76 & $3.44 \times 10^{-15}$ \\
\hline
\end{tabular}

*For the models of Polley et al. (2002) and Nars and Givi the units of $\gamma$ are $\left(\mathrm{m}^{2} \mathrm{~K} / \mathrm{J}\right)$

\section{FOULING MITIGATION}

Mechanical cleaning of heat exchangers is one of the commonest strategies used in the industry to attempt to address the fouling challenge. However, the route is followed when it becomes obvious that the cost associated with energy loss have become profound. Hence, this makes the method a reactive strategy instead of the preferred proactive strategy. Nesta and Bennett (2005) postulated that in other to mitigate fouling, design should maximize shear stress and as well as control wall temperature. The study also recommended replacing the use of fouling factors with $20 \%$ excess area. The implication of this recommendation is that the capital cost of heat exchangers will increase by $20 \%$. This increase in surface area does not really eliminate fouling but only attempts to delay the emergence of fouling to a later date. In a different approach, Klaren et al. (2007) designed a "zero fouling" self-cleaning heat exchanger. A heat exchanger may be classified as "zero fouling" if it services severe fouling media at both sides of the heat transfer surface and shows no measurable decrease in the heat transfer coefficient over a continuous operating period that may last several years. The design was based on the concept of "let fouling happen," but it removes the fouling deposits as they are being formed and on the circulation of fluidized solid particles in the tubes. According to the research, successfully operating self-cleaning (fluidized bed) heat exchangers have been applied in numerous high fouling services involving processes such as waste water, oil and clean water, where it was noted to increase or restore the heat transfer coefficient, $\mathrm{K}$. This new zero fouling self-cleaning design has been compared with a conventional severe fouling crude oil preheater, and it has been shown that a reduction in required heat transfer surface from $700 \mathrm{~m}^{2}$ for the conventional exchanger to $229 \mathrm{~m}^{2}$ for the newly designed heat exchanger can be achieved. This self-cleaning heat exchange technology has already realized very large savings in other industrial applications that suffer from severe fouling heat exchangers (Klaren and Sullivan, 2001). However, this can only be employed in low velocity flows and in shell and tube exchangers. In addition, its application in the design of other types of heat exchanger outside of shell and tube is yet to be experimented. 
In another work on the development of mitigation to heat exchanger fouling, Benzinger et al. (2005) carried out a study on the influence of ultrasound in microstructure heat exchanger. For the investigation, an electrically heated micro heat exchanger was developed. A solution of calcium nitrate/sodium hydrogen carbonate was pumped through the channels of a micro-structured device at a mass flow rate of $1.5 \mathrm{~kg} / \mathrm{h}$. The temperature causes the precipitation of solid calcium carbonate on the surface. This results in a decreasing heat transfer coefficient. An ultrasonic pulse of $1 \mathrm{~min}$ duration breaks up the fouling layer and the heat transfer coefficient reaches again its starting value. Moreover, a comparison of each cycle shows that after each ultrasonic pulse the heat transfer coefficient decreased with a higher rate than the previous cycle. Also, a decrease of the outlet temperature to lower values was found. Wilson (2003) performed a study on the cleaning in place programme for the heat exchanger. The study identified that the key factor in developing cleaning protocol is the nature of the fouling deposit as this will determine the most appropriate cleaning technique. The links between fouling and cleaning should be appreciated, particularly where ageing processes can significantly affect the nature of deposit. Such links indicate that fouling and cleaning should both be considered during equipment design.

Master et al. (2003) recognized that poor heat exchanger geometry leading to misdistribution of flow, wakes and eddies have detrimental effect on heat exchanger performance and reliability. Hence, the study designed a Helixchanger heat exchangers that demonstrated significant improvements in the fouling behaviour of heat exchangers in operation with an option to reduce the velocity-dependent fouling in heat exchangers. In a Helixchanger heat exchanger, the quadrant shaped shell side baffle plates are arranged at an angle to the tube axis creating a helical flow pattern on the shell side. The study however pointed out that proper attention was required in designing the heat exchangers placed at the hot end of crude oil pre-heat operations where temperatures and velocity thresholds are highly dependent on heat exchanger geometry. The helical baffle design offers great flexibility in selecting the optimum helix angles to maintain the desired flow velocities and temperature profiles to keep the conditions below the "fouling thresholds". Nesta and Bennett (2005) established that fouling mechanisms can be mitigated with proper design strategy. It recommended replacing the use of fouling factors with $20 \%$ excess area and that the application of this field-proven design methodology will significantly lower capital costs and substantially increase run time between cleanings. The study proposed that regardless of service, the desire will be to minimize wall temperature and maximize shear stress by maximizing fluid velocity. It is also to distribute pressure drop across trains to maximize velocity in problematic exchangers when possible. Material selection also has a pronounced effect on fouling, particularly when biological fouling is a concern. In a related study, Ishiyama et al. (2007) reported the development of a highly flexible preheat train simulator constructed in MATLAB/Excel. It could accommodate variable throughput, control valve operation and different cost scenarios. Accordingly, the simulator was tested successfully for the scheduling of cleaning operations. In another study, Demirskiy et al. (2018) demonstrated that fouling mitigation in plate heat exchanger is possible if the wall shear stress can be increased at uniform pressure drop. The report also corroborated Labbadlia et al. (2017) on the impact of arrangement on heat exchanger performance.

\section{FOULING THRESHOLD}

Fouling threshold has been defined as the maximum wall temperature, at a particular flow velocity, below which substantial deposit accumulation will not occur. The locus of the fouling threshold conditions splits the operational area into two sections as shown in Fig. 1.

The severity of the deposition will decrease as the operating conditions are moved closer to the threshold. In the case that the operating conditions move below the threshold line, negligible fouling deposition can be expected. Fig. 1 shows that the changes required to move the operating point towards the region of favourable conditions imply either increasing the flow velocity, decreasing the wall temperature or a combination of both. The 'fouling threshold' concept, proposed by Ebert and Panchal (1995), advocates that fouling due to chemical reaction in a crude oil heat exchanger is due to two contrasting processes known as "formation and removal". Consequently, the rate of formation depends on the temperature of the heat transfer surface while the rate of removal depends on flow velocity. Rodriguez and Smith (2007) suggested a new technique in addressing fouling in heat exchangers. It involved tackling fouling from a proactive standpoint, instead of concentrating efforts on assuaging the impact of fouling depositions. This method is intended to prevent its manifestation and combines the optimization of operational conditions with managing the cleaning activities in an all-inclusive mitigation approach. It defined a fouling threshold as the maximum wall temperature, for a given flow velocity, below which significant deposition does not take place.

In further study regarding fouling threshold, Yang et al. (2011) studied threshold conditions of crude oil fouling using a batch-stirred cell system $(\sim 1$ litre $)$ at surface temperature of about $400^{\circ} \mathrm{C}$ and pressure of approximately 30 bar. Negative rate of fouling resulted at a reduced surface temperature as well as increase in speed of stirring after the heat transfer surface has witnessed substantial fouling, meaning, the fouling resistance had risen to greater level. The results are displayed in Fig. 2.

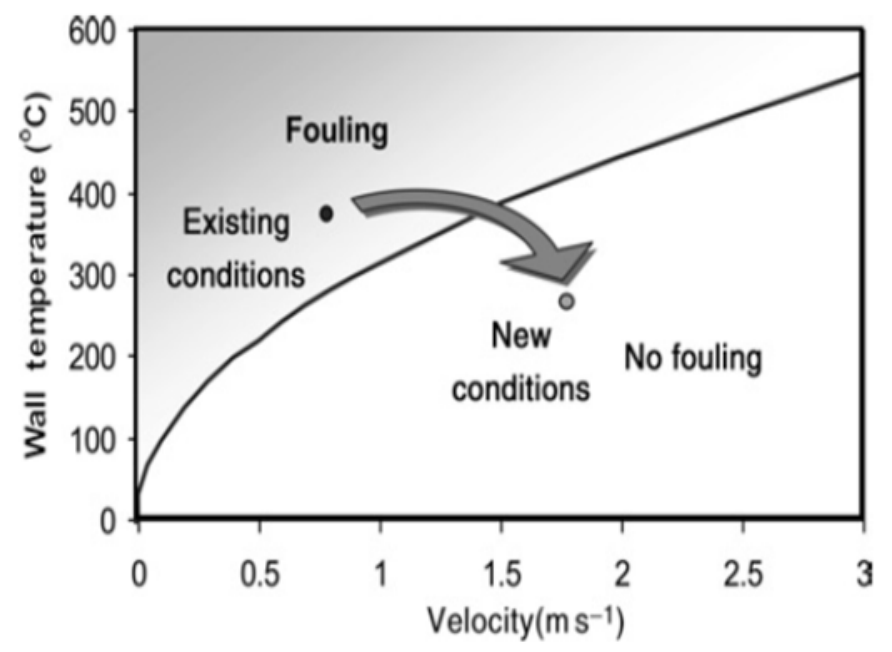

Fig. 1 Changing Operating Conditions to Mitigate Fouling (Rodriguez and Smith, 2007).

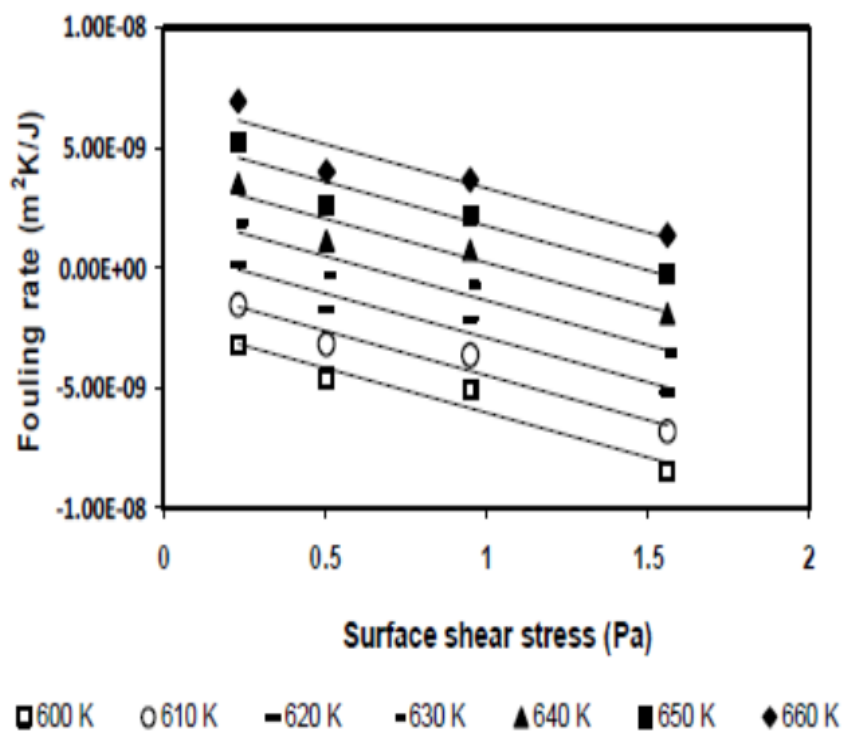

Fig. 2 Fouling Rate versus Surface Shear Stress (for various Initial Surface Temperatures) (Yang et al., 2011) 
According to Yang et, al., (2011), records gathered from experimentations that result in positive fouling rate and negative fouling rates covering series of surface temperature and shear stress values have been found to allow quicker establishment of the fouling threshold conditions with greater precision. This is achieved by the interpolation of the rate of fouling data instead and not by the extrapolation of the positive fouling data alone to zero-rate conditions. Fig. 3 illustrates the threshold conditions of fouling covering four wall temperatures. Thus, the surface shear stress cum fouling rate curve moves from positive fouling rates to negative values.

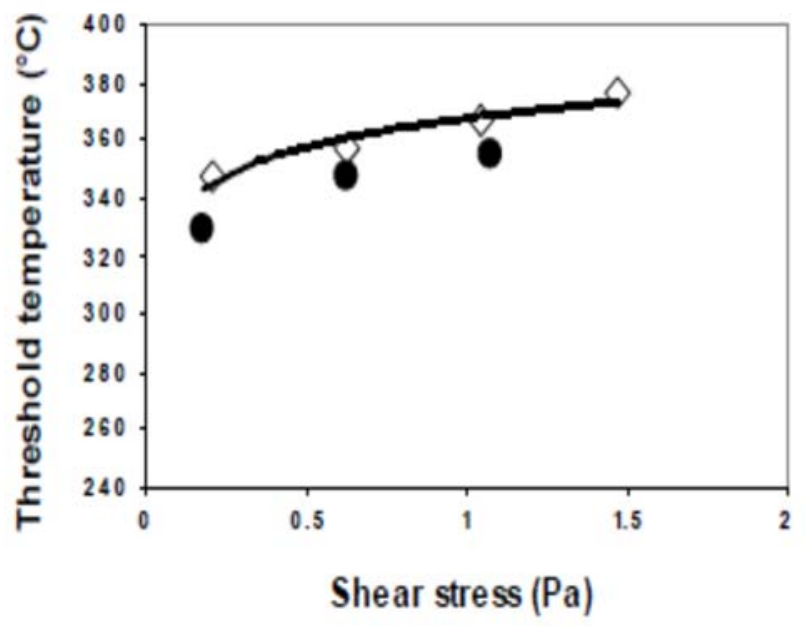

Fig. 3 Threshold temperature (Yang et al., 2011)

\section{MODELS FOR PREDICTING FOULING}

The most common fouling model is attributed to Ebert and Panchal (1997) as shown in eq. 7 :

$$
\frac{\mathrm{dR}_{\mathrm{f}}}{\mathrm{dt}}=\mathrm{A}_{\mathrm{I}} \mathrm{Re}^{-0.66} \operatorname{Pr}^{-0.33} \exp \left(-\mathrm{E}_{\mathrm{I}} / \mathrm{RT}_{\mathrm{f}}\right)-\mathrm{C}_{\mathrm{I}} \tau_{\mathrm{w}}
$$

where: $\mathrm{A}=$ deposition constant, $\mathrm{E}=$ activation energy and $\mathrm{Pr}=$ Prandtl number, $\mathrm{Re}=$ Reynold's number, $\mathrm{C}_{\mathrm{I}}=$ fouling parameter, $\mathrm{T}_{\mathrm{f}}=$ filmtemperature and $\tau_{\mathrm{w}}=$ shear at the deposit surface.

Ebert and Panchal (1997) initially predicted rate of deposition using film temperature but in recent researches, Heat Transfer Research Incorporated (HTRI) established the rate of deposition using the skin temperature as it presents better trending than with film temperature (Lestina and Zettler, 2014). According to the study, high variability in activation energy is a challenge. Different researchers have proposed different numbers. Ebert and Panchal (1997) evaluated a particular crude oil using activation energy of $69 \mathrm{~kJ} / \mathrm{mole}$. However, recent HTRI study of four crude oil samples discovered activation energy values spanning from $128 \mathrm{~kJ} / \mathrm{mole}$ to $269 \mathrm{~kJ} / \mathrm{mole}$ (Lestina and Zettler, 2014). As a follow up to the model of Eq. (5), Polley et al. (2005) developed a simpler model which provides rational alignment with comprehensive simulations as well as allow the consideration of the temperature ranges within a unit instead of focusing on a point. The model is represented as Eq. (8):

$$
\frac{\mathrm{dR}_{\mathrm{f}}}{\mathrm{dt}}=\mathrm{A}_{\mathrm{II}} \operatorname{Re}^{-0.8} \operatorname{Pr}^{-0.33} \exp \left(\frac{-E_{I I}}{\mathrm{RT}_{\mathrm{s}}}\right)-\mathrm{C}_{\mathrm{II}} \mathrm{Re}^{0.8}
$$

Eq. (8) is termed the Engineering Sciences Data Unit (ESDU) model. It differs primarily in the use of the surface temperature, $T_{\mathrm{s}}$, in the deposition term, and suppression based on friction velocity or Reynolds number rather than wall shear stress. According to the study, "the fouling model can be used to specify which approach should be followed when operating outside threshold fouling. This strategy requires the use of tube inserts or initiation of consistent cleaning". Further to the previous studies that proposes that the initial fouling rates increases with increasing surface temperature or bulk temperature of crude oil, Shetty et al. (2016) proposed a model which uses effective film temperature $\left(\mathrm{T}_{\text {eff }}\right)$ in the Arrhenius expression.

$$
\begin{gathered}
\mathrm{T}_{\text {eff }}=\alpha_{1} \mathrm{~T}_{\mathrm{s}}+\alpha_{2} \mathrm{~T}_{\mathrm{b}} \\
\frac{\mathrm{dR}_{\mathrm{f}}}{\mathrm{dt}}=\alpha \operatorname{Re}^{\beta} \operatorname{Pr}^{-0.33} \exp \left[\frac{-\mathrm{E}}{\mathrm{RT}_{\mathrm{eff}}}\right]-\gamma \tau_{\mathrm{w}}
\end{gathered}
$$

where $T_{s}$ and $T_{b}$ are surface and bulk temperature respectively, $\alpha_{1}$ and $\alpha_{2}$ are constants and $\alpha$ is Deposition constant $\left(\mathrm{m}^{2} . \mathrm{k} / \mathrm{kW}\right.$.min). The study used three different crude oils with varying operating conditions of surface and bulk temperatures and velocities. According to the study, the fouling rate predicted by the model closely aligns with the data obtained from experimental studies using a fouling test rig with a double pipe heat exchanger.

Moreover, previous study by Malayeri and Müller-Steinhagen (2001) presented the use of Neural Network Analysis for the prediction of fouling behaviour under subcooled flow boiling. It reported the advantages and disadvantages of the neural network architecture when the technique was applied to fouling data. It has been shown that the predictability of the network is promising when dominant variables are known and also adequate data are presented to the network. Brahim et al. (2003) contributed to the fouling prediction by using a Computational Fluid Dynamics (CFD) solver to predict the growth of crystals on flat and structured surfaces of heat transfer equipment. According to the reports, the simulation does not support what was called calculation of the fouling process. The numerical simulation resulted in the forecast of the fouling resistance over certain period. The simulation however tends in most cases to underestimate the fouling behaviour. Reason for that was the fact that the CFD solver employed computes too small values of the temperature at the phase boundary crystal layer/salt solution. Liporace and de Oliveira (2005) developed a tool to evaluate the performance of a crude oil preheat train on a-real-time basis. The tool used complex process simulation as well as complicated heat exchanger design to ensure that accurate global heat transfer coefficient (operational and clean modes) and fouling factor can be evaluated. This was done using a process simulator called Petrox from Petrobras and HTRI, and obtained fouling factors close to real life values. This has contributed to the improvement of heat exchanger design performance.

Polley et al. (2005) presented a partial simulation model incorporating a linear temperature distribution as against using data collected at what may be point or localized conditions. It tested the reliability of the proposed model taking into consideration drop in pressure. The short cut model was incorporated into ESDU's EXPRESS ${ }^{\mathrm{TM}}$ program package which allows the determination of which fouling model fits the data better in each situation and generates the associated fouling model parameters. The result showed that the model gave reasonable agreement with the detailed simulations but the fouling model developed by Ebert and Panchal (1997) gives better description of the observed fouling behaviour. Polley et al. (2007) developed a means of simultaneously simulating the effects of fouling on overall pressure drop, flow distribution and thermal performance of pre-heat trains of a refinery. It recognized that, the heat transfer fouling resistance, $R_{\mathrm{f}}$, is related to the deposit thickness, $\delta$, and the thermal conductivity of the deposit, $\lambda_{\mathrm{f}}$, mathematically via the thin slab approximation:

$$
\mathrm{R}_{\mathrm{f}} \approx \frac{\delta}{\lambda_{\mathrm{f}}}
$$

Furthermore, the study utilized the uniform roughened core model given by Eq. (12) to determine the hydraulic effects of fouling.

$$
\frac{\Delta \mathrm{P}_{\text {fouled }}}{\Delta \mathrm{P}_{\text {clean }}}=\frac{\mathrm{f}_{\text {fouled }}}{\Delta \mathrm{f}_{\text {clean }}}\left(\frac{\mathrm{d}_{\mathrm{i}}}{\mathrm{d}_{\mathrm{i}}-2 \delta}\right)^{5}
$$


where $\Delta \mathrm{P}$ is pressure drop, $\mathrm{f}$ is the friction factor, $\delta$ is the deposit thickness, $d_{i}$ is the tube diameter. According to the study, with this simulation it is possible to:

- Identify whether throughput will be restricted by the hydraulic effects of fouling or by difficulties in maintaining process operating temperatures (desalted temperature, pre-flash column temperature or furnace inlet temperature).

- Know the plant throughput that can be achieved when one or more exchangers are isolated for cleaning.

- Know the cost benefits of cleaning in terms of energy saving or improved throughput.

Gudmundsson et al. (2009) came up with an off-line method for detecting fouling in a cross-flow heat exchanger by using measurements that are gathered in normal operation of the heat exchanger. The model was eventually based on simulated data of cross-flow heat exchanger with water on both sides. The conclusion was that it is possible to detect fouling in cross-flow heat exchanger with the derived method, with reasonable accuracy and consistency. In other to address the prohibitive computer time required in the application of a fouling model in either heat exchanger design or in the simulation of pre-heat train performance requiring integration over both space and time, Polley and GonzalesGarcia (2009) presented a simple approach that eliminates the need to integrate-over the exchanger space. According to the study, when compared with a full space-time analysis of the performance of an industrially sized multi-pass heat exchanger, the results demonstrated the validity of the approach within expected accuracy of the predictions of a fouling model. The procedure has been applied to the difficult task of a fouling model that has a sudden limiting condition (such as that observed in exchangers fitted with Turbotal inserts).

While contemporary approaches are adequate for comparative study of fouling phenomenon, Lestina and Zettler (2014) believe that there is no general method to predict fouling tendency. Existing prognostic fouling models have limitations in their use, and series of advancements are being carried out based on chemical characterization (Lestina and Zettler, 2014). Kaneko et al. (2009) constructed statistical models (using chemoinformatics methods) with linear (partial least squares method) and nonlinear regression methods (support vector regression method) to predict fouling potential. The parameters inputted into the models were obtained from experiments. These include some typical parameters for example, the degree of super saturation. Certain parameters like the fouling resistance $\mathrm{R}_{\mathrm{f}}$ were calculated using the models and the output values were in alignment with those from experiments. Therefore, the study established that the statistical models in Eqs. (13) and (14) predicted the fouling phenomena with high accuracy. However, the model has not been tested with crude oil.

$$
\mathrm{y}=\mathrm{Xb}+\text { Constant }
$$

$$
\mathrm{b}=\mathrm{W}\left(\mathrm{P}^{1} \mathrm{~W}\right)^{-1} \mathrm{q}
$$

where $\mathrm{W} \in R \mathrm{a}$ is an $\mathrm{x}$-weight matrix and $\mathrm{b} \in R$ is a vector of regression coefficients; $\mathrm{P} \in R \mathrm{a}$ is an $\mathrm{x}$-loading matrix; $\mathrm{q} \in R$ is a y loading vector.

The key goal of an organization is to come to the point of being able to leverage on models to predict fouling and make important cleaning related decisions. Another advantage of such models is to be able to predict fouling behaviour before a crude (or blend) is even processed (Joshi, 2013). It has been noted that available field data come from relatively unstable plant operating mode and not essentially agreeable to models which depend on very precise measurements of properties and other operating conditions like flow rates and temperatures. It is difficult to apply models developed from data taken under ideal conditions and used in pilot plant measurements (Joshi, 2013). According to the study, many models to predict fouling in crude oil systems have been suggested but a lot of them assumed there be will reaction by a precursor. It offered a pilot model in Eq. (15) which relies on surface roughness in addition to shear stress to correlate deposit accumulation and a parameter for ageing to forecast the thermal conductivity of the deposition. The model assumed that no hydrocarbon components such as polymer and/or asphaltenes are the precursors to fouling except the crude oil. The model is represented as Eq. (15):

$$
\begin{aligned}
& \mathrm{R}_{\mathrm{f}}=\left(\mathrm{A}_{1} * \mathrm{t} * \tau^{-\mathrm{A} 2} * \mathrm{P}[\mathrm{t}]\right) /(\mathrm{K} * \rho) \\
& \mathrm{K}=\left(\mathrm{K}_{\mathrm{a}}-\mathrm{A} 4 * \mathrm{e}^{-\mathrm{t} * \mathrm{~A} 3 * \mathrm{Tw}} *\left(\mathrm{~K}_{\mathrm{a}}-\mathrm{K}_{\mathrm{c}}\right)\right)
\end{aligned}
$$

where $R_{f}=$ the fouling resistance, $t=$ time, $\tau=$ shear stress at the wall, $P$ $=$ roughness parameter which is a function of time, $\mathrm{k}=$ thermal conductivity of the deposit, $\rho=$ density of the crude, $k_{a}=$ aged (final) thermal conductivity of the deposit, $\mathrm{T}_{\mathrm{s}}=$ surface temperature, and $\mathrm{k}_{\mathrm{c}}=$ thermal conductivity of the crude. $\mathrm{A}_{1}, \mathrm{~A}_{2}, \mathrm{~A}_{3}$ and $\mathrm{A}_{4}$ are fit constants. It is assumed that the roughness parameter fluctuates in such a way that it gets to a highest asymptotic value. It is important to note that a substantial gap still exists between real-time operating parameters and those from any laboratory or pilot-scale set up, especially with respect to varying conditions and trends that can be used (Joshi, 2013).

Andrjesdóttir et al. (2011) applied a lock-in technique to spot fouling in a heat exchanger. The basis of the technique was the concept of lock-in amplifier channels as deployed in applications that reduces signal noise. According to the study, the sensitivity of the technique is much more than that of effectiveness evolution. It also stated the possibility of differentiating between the effects of fouling and the effect of decrease in fluid flow rate. Morimoto et al. (2011) studied crystallization fouling leveraging on various devices like the plant, bench scale and laboratory scale. These were aimed at determining factors such as temperature, surface roughness and liquid velocity. The study developed a new model called the Kern-Seaton-Reitzer model to calculate the rate of crystallization fouling. It came up with the following models for shell and tube heat exchanger set ups:

i. Bench-size simulator

$$
\frac{\mathrm{dR}_{\mathrm{f}}}{\mathrm{dt}}=0.015\left(\frac{\mathrm{Q} / \mathrm{A}}{\mathrm{hi}}\right)^{1}-8 \mathrm{u}^{2} \mathrm{x}_{\mathrm{f}}^{2}
$$

ii. Lab-size simulator

$$
\frac{\mathrm{dX}_{\mathrm{f}}}{\mathrm{dt}}=5 \times 10^{-5}(\Delta \mathrm{C})^{1}-3 \mathrm{X} 10^{-6} \mathrm{\tau X}_{\mathrm{f}}^{2}
$$

where $\mathrm{X}_{\mathrm{f}}$ is fouling thickness $(\mathrm{m}), \Delta \mathrm{C}$ is supersaturation, $\mathrm{A}$ is the heattransfer area $\left(\mathrm{m}^{2}\right), \mathrm{h}_{\mathrm{i}}$ is the heat-transfer coefficient, $T$ is shear rate, $\mathrm{R}_{\mathrm{f}}$ is fouling resistance, and $u$ is the overall heat-transfer coefficient.

However, according to the study, there was disagreement between the operating plant parameters and those of the testing unit, possibly due to scale formation. It then built another device capable of estimating crystallization fouling based on shear rate.

Liporace and Oliveira (2005) described an on-line heat exchanger performance evaluation system based on rigorous simulation of the equipment in order to predict both the operational and clean overall heat transfer coefficient. The study was carried out in response to concerns on fouling in preheat trains in Petrobras' refineries. It found that a real-time comparison between the operational and clean overall heat transfer coefficient values indicates the actual performance of the heat-exchanger and that of the preheat train. It utilized a process simulator together with Xist program from HTRI to allow them to consider various aspects 
during the evaluation. When the results and trends are fed into the refinery, it helps determine when to remove fouled heat-exchangers for maintenance cleaning. Fouling factor values close to real values from Petrobras were obtained, hence providing an opportunity to improve the design of future heat exchangers.

Sileri et al. (2009) developed a mathematical model to establish deposition and removal rates of asphaltene in pre-heat trains in quantitative and qualitative terms. The principles that formed the basis of their model include conservation of mass, momentum, energy and chemical equilibrium (accounting for phase separation \& deposit accumulation due to heat-induced instability). Accordingly, the model takes cognizance of fouling material deposited inside the conduits, impact of their age, and their detachment from the wall via hydrodynamic contacts with the bulk fluid. From the various simulations, it became clear that age-related effects exacerbate fouling. Graphical representations of fouling deposition as a function of time indicate the possibility of total deposit removal without aging. However, in the presence of these phenomena, the outcomes show the steady accumulation of deposit thickness on the walls of the conduit with potential for complete blockage of the conduits. Most models focus on fouling inside the tubes while fouling on the shell side has not receive commensurate attention.

Diaz-Bejarano and Colleti (2015) recognized that fouling deposition on the shell side should not be neglected. Therefore, the study leveraged on a model called Hexxcell Studio to capture fouling of the shell side of a shell tube exchanger. The simulation showed some interaction between fouling within and outside of the tubes and establishes impact of fouling on flow patterns, heat transfer coefficient and pressure drops. Ho (2016) examined the behaviours of five crude oil whose effluent temperatures decline because of foulant deposition on the wall, in the laboratory. The study developed a fouling model for the analysis of the behaviour of crude oil and interpretation of fouling data obtained with a widely used laboratory unit. According to the study, the model analyzes fouling growth rate in a shell and tube heat exchanger from temperature timeseries data and the fouling dynamics is governed by a fouling-property correlation as represented in the Eq. (19).

$\mathrm{FPI}=\left[2.4+\frac{\mathrm{NHI}}{\mathrm{S}_{\mathrm{BN}}-\mathrm{I}_{\mathrm{N}}}\right]-\left[\left(\mathrm{S}_{\mathrm{BN}}-\mathrm{I}_{\mathrm{N}}\right)+\mathrm{TBN}+1.2\left(\mathrm{~N}_{\mathrm{i}}+\mathrm{V}\right)\right]$

where $\mathrm{NHI}$ is $\mathrm{n}$-heptane insoluble, $\mathrm{SBN}$ is solubility blending number, $\mathrm{I}_{\mathrm{N}}$ is the insolubility parameter, $\mathrm{TBN}$ is total base number and $\mathrm{Ni}+\mathrm{V}$ is a combination of Nickel and Vanadium which are structural components of crude oil. In a more recent study, Lemos et al. (2017) stated that heat exchanger design practice use uniform values known as fouling factors to develop standard heat exchanger products. It further highlighted the fact that the rate of fouling in a particular heat exchanger apparatus depends greatly on the dynamic properties of the thermofluid, with the flow velocity having a major impact. The study demonstrated in addition, the benefit of including models into the design phase and introduced a modified linear model that aided the determination of the optimum design parameters.

Various other methods exist which include the neural networks (Riverol and Napolitano, 2005), wavelets (Ingimundardóttir and Lalot, 2011), linear parameter varying (LPV) models (Mercère et al., 2013), fuzzy observers (Delmotte et al., 2008), physical model (Gudmundsson et al., 2009), and Extended Kalman filters (Jonsson et al., 2007). Moreover, Wen et al. (2017) employed a multi-resolution wavelet neural network approach for the prediction of fouling resistance of a plate heat exchanger. The feed forward wavelet neural network developed in the study gave better prediction than other neural network methods tested, thereby highlighting the importance of accurate prediction of fuling. However, these and other methods are primarily intended to forecast when to start a maintenance process as a specified fouling factor is reached. Ultimately, this helps plant management team to migrate from curative to predictive maintenance philosophy.

\section{CONCLUSION}

Being able to predict fouling rate in heat exchangers in various applications operating under diverse operating conditions remains the ultimate desire of any player in the industry where heat transfer processes are prevalent. Understanding the concept of fouling and the interactions among various parameters is critical to achieving this. Based on the literatures reviewed, there is no single model that has provided an accurate prediction of fouling in all the different types of heat exchangers. A few organizations have developed proprietary models or software following standard heat transfer principles. However, most of the models were tested on shell and tube heat exchangers. The accuracies of such software in evaluating the performance and behaviour of plate and frame heat exchangers for example are yet to be understood. According to Joshi et al. (2009), crude oil fouling research should be directed to reflect the fouling behaviour of operating exchangers. Available researches only considered experiments in small laboratory scale test sections such as heated rods and short tubular sections.

\section{ACKNOWLEDGEMENTS}

The authors wish to thank the management and board of Regent of Covenant University, Ota, Nigeria for the part sponsorship of the research study.

\section{REFERENCES}

Abd-Elhady M. S., Rindt C. C. M and Van Steenhoven A. A. 2009. "Optimization of Flow Direction to Minimize Particulate Fouling of Heat Exchangers," Heat Transfer Engineering, 30 (10-11) 895-902. https://doi.org/10.1080/01457630902754142

Abd-Elhady M.S., Rindt C.C.M, and. Van Steenhoven A.A 2007. "Optimization of Flow Direction to Minimize Particulate Fouling of Heat Exchangers," Proc. of 7th International Conference on Heat Exchanger Fouling and Cleaning - Challenges and Opportunities. Vol RP5, Article 46. https://doi.org/10.1080/01457630902754142

Akınç H. E, Becer M., Bakır M., Özçelik Y., and Balkan F 2013. "Fouling Monitoring in Crude Oil Preheat Trains," Proc. on Heat Exchanger Fouling and Cleaning - 2013, Budapest, Hungary.

Al-Janabi A., Esawy M., Malayeri M.R. and Müller-Steinhagen H. 2009. "Consideration of Dynamic Uncertainty in Fouling Experimentation," Proc. of International Conference on Heat Exchanger Fouling and Cleaning VIII - June 14-19, 2009, Schladming, Austria.

Andrjesdottir, O., Pálsson, H., Lalot, S. and Desmet, B. 2011. "Detection of fouling in a heat exchanger by application of a lock-in technique," Proc of International Conference on Heat Exchanger Fouling and Cleaning IX, Crete, June.

Barrie P.J., Pittas C.A., Mitchell M.J. and Wilson D.I. 2011. "A Critical Analysis of the Compensation Effect and its Application to Heat Exchanger Fouling," Proc. Heat Exchanger Fouling and Cleaning IX 05-10 June 2011, Crete Island, Greece.

https://doi.org/10.1080/01457632.2012.741029

Bennett C. A., R. S. Kistler, Nangia K., Al-Ghawas W., Al-Hajji N., and Al-Jemaz A. 2007. "Observation of an Isokinetic Temperature and Compensation Effect for High Temperature Crude Oil Fouling," Proc. Heat Exchanger Fouling and Cleaning - Challenges and Opportunities. [2007], Vol. RP5, Article 7.

Benzinger W., Schygulla U., Jäger M. and Schubert K. 2005. "AntiFouling Investigations with Ultrasound in a Microstructured Heat 
Exchanger," Proc. on Heat Exchanger Fouling and Cleaning Challenges and Opportunities, [2005], Vol. RP2, Article 29.

Bories, M. and Patureaux T. 2003. "Preheat Train Crude Distillation Fouling Propensity Evaluation by the Ebert and Panchal Model," Refereed Proc of Heat Exchanger Fouling and Cleaning: Fundamentals and Applications Engineering Conferences International -2003. [http://dc.engconfintl.org/cgi/viewcontent.cgi? article $=1026 \&$ context $=\mathrm{h}$ eatexchanger, accessed Nov. 21, 2017]

Brahim F. Augustin W, Bohnet M. 2003. "Numerical Simulation of the Fouling on Structured Heat Transfer Surfaces (Fouling)," Proc. Heat Exchanger Fouling and Cleaning: Fundamentals and Applications. Art. 17 [2003].

[http://dc.engconfintl.org/cgi/viewcontent.cgi?article $=1016 \&$ context $=\mathrm{h}$ eatexchanger, accessed Nov. 21, 2017]

Costa A. L. H., Tavares V. B. G., Queiroz E. M., Pessoa F. L. P, Liporace F. S., Oliveira S. G. and Borges J. L. 2011. "Analysis of the Environmental and Economic Impact of Fouling in crude Preheat Trains for Petroleum Distillation," Proc. of International Conference on Heat Exchanger Fouling and Cleaning - June 05 - 10, 2011, Crete Island, Greece. [http://www.heatexchangerfouling.com/papers/papers2011/7_Costa_Environmental\%20and\%20Ec onomic\%20Impact\%20of\%20Fouling_F.pdf, accessed Nov. 21, 2017]

Costa, A.L.H., Tavares, V.B.G., Borges J.L., Queiroz, E.M., Pessoa, F.L.P., Liporace, F.S. and Oliveira, S.G. 2011. "Parameter Estimation of Fouling Models in Crude Preheat Trains," Proceedings of International Conference on Heat Exchanger Fouling and Cleaning - 2011 June 05 10, 2011, Crete Island, Greece

https://doi.org/10.1080/01457632.2012.738566

Crittenden B. D., Kolaczkowski S. T., Takemoto T. and Phillips D. Z. 2007. "Crude Oil Fouling in a Pilot-Scale Parallel Tube Apparatus," Proc. of 7th International Conference on Heat Exchanger Fouling and Cleaning - Challenges and Opportunities, [2007], Vol. RP5, Article 5. http://dc.engconfintl.org/heatexchanger2007/5

https://doi.org/10.1080/01457630902744135

Delmotte, F., Delrot S., Lalot, S., and Dambrine, M., 2008. "Fouling detection in heat exchangers with fuzzy models," Proc. of the 19th International Symposium on Transport Phenomena, 17-21 August, 2008, Reykjavik, Iceland.

Demirskiy, O.V., Kapustenko, P.O., Arsenyeva, O.P., Matsegora, O.I. and Pugach, Y.A. 2018. "Prediction of fouling tendency in PHE by data of on-site monitoring. Case study at sugar factory," Applied Thermal Engineering, 1281074 - 1081.

https://doi.org/10.1016/j.applthermaleng.2017.09.087

Diaz-Bejarano, E., Coletti, F., 2015. "Modelling Shell-Side Crude Oil Fouling in Shell-And-Tube Heat Exchangers," Proc. of International Conference on Heat Exchanger Fouling and Cleaning - June 07 - 12, 2015, Enfield (Dublin), Ireland.

Diaz-Bejarano, E., Coletti, F. and Macchietto, S., 2015. "Crude Oil Fouling Deposition, Suppression, Removal - and how to Tell the Difference," Proc. of International Conference on Heat Exchanger Fouling and Cleaning - June 07 - 12, 2015, Enfield (Dublin), Ireland. https://doi.org/10.1080/01457632.2016.1206408

Dickakian, G., and Seay, S., 1988. "Asphaltene precipitation primary crude exchanger fouling mechanism," Oil Gas Journal. 86 (10), 47-50
Ebert, W. and Panchal, C.B., 1995. "Analysis of Exxon crude-oil slip stream coking data," Proc. Mitigation of Fouling in Industrial Heat Exchanger, 1995, San Luis Obispo, USA, 451-460.

Ebert, W. and Panchal, C.B., 1997. "Analysis of Exxon crude-oil slip stream coking data", in Fouling Mitigation of Industrial Heat Exchange Equipment, Panchal, C.B., Bott, T.R., Somerscales, E.F.C. and Toyama, S. (eds.), Begell House, NY, 451-460.

Epstein, N., 1994. "A model of the initial chemical reaction fouling rate for flow within a heated tube, and its verification", Proc. 10th Int. Heat Trans. Conf., Brighton, IChemE, 4, 225-229.

Epstein N. 1999. "Types of fouling” In Knudsen, J.G., Hays, G.F. and Bott, T.R. (ed.), Fouling in Heat Exchanger. Beggel House Inc. [http://dl.begellhouse.com/download/issue/20945f8470416592/sample. pdf, accessed Nov. 21, 2017]

Geddert, T., Augustin, W. and Scholl, S. 2009. "Influence of Surface Defects and Aging of Coated Surfaces on Fouling Behavior," Proc. of International Conference on Heat Exchanger Fouling and Cleaning VIII - 2009 (Peer-reviewed) June 14-19, 2009, Schladming, Austria. https://doi.org/10.1080/01457632.2010.495629

Fu, L., Liu, P. and Li, G. 2017. "Numerical investigation on ash fouling characteristics of flue gas heat Exchanger," Applied Thermal Engineering, $123891-900$.

https://doi.org/10.1016/j.applthermaleng.2017.05.184

Gudmundsson O., Lalot S. and Thorsen J.E. 2013. "Comparison of Fouling Detection Methods using Experimental Data," Proc. on Heat Exchanger Fouling and Cleaning X - 2013 09-14 June, Budapest, Hungary.

http://www.heatexchanger-fouling.com/

Gudmundsson, O., Palsson, O.P., Palsson, H. and Lalot, S. 2009. "Fouling Detection in a Cross-Flow Heat Exchanger Based on Physical Modeling," Proceedings of International Conference on Heat Exchanger Fouling and Cleaning VIII - 2009 (Peer-reviewed) June 14-19, 2009, Schladming, Austria. [http://www.heatexchangerfouling.com/papers/papers2009/63_Gudmundsson_F.pdf, accessed Nov. 21, 2017]

Gudmundsson O., Palsson O.P., Palsson H. and. Jonsson G.R 2011. "Comparison of Fouling Detection between a Physical Model and a Black Box Method," Proc. on Heat Exchanger Fouling and Cleaning IX - 2011 05-10 June, Crete Island, Greece. [http://www.heatexchangerfouling.com/papers/papers2011/57 Gudmundsson F.pdf, accessed Nov. 21, 2017]

Heins A, Veiga R., Ruiz C., Riera A. 2007. "Fouling Monitoring and Cleaning Optimisation in a Heat Exchanger Network of A Crude Distillation Unit," Proc. of Heat Exchanger Fouling and Cleaning Challenges and Opportunities. [2007], Vol. RP5, Article 59. [https://web-

material3.yokogawa.com/2007_HXs_Fouling_Monitoring_Soteica_Re psolYPF.pdf?_ga=2.143267445.1533720747.1511266454-

1816117946.1511266454, accessed Nov. 21, 2017]

Ho, T.C., 2016. "A study of Crude Oil Fouling Propensity," International Journal of Heat and Mass Transfer, 95, 62-68. https://doi.org/10.1016/j.ijheatmasstransfer.2015.11.086

Ingimundardóttir, H. and Lalot, S. (2011). Detection of Fouling in a Cross-Flow Heat Exchanger Using Wavelets, Heat Transfer Engineering, Vol. 32, Issue 3-4, 349-357. 


\section{https://doi.org/10.1080/01457632.2010.495668}

Ishiyama E. M., Paterson W. R., Wilson D. I. 2007. "The Effect of Fouling on Heat Transfer, Pressure Drop and Throughput in Refinery Preheat Trains: Optimization of Cleaning Schedules," Proc. of 7th International Conference on Heat Exchanger Fouling and Cleaning Challenges and Opportunities. [2007], Vol. RP5, Article 9. https://doi.org/10.1080/01457630902751486

Jonsson, G. R., Lalot, S., Palsson, O.P., and Desmet, B. 2007. "Use of Extended Kalman Filtering in Detecting Fouling in Heat Exchangers," International Journal of Heat and Mass Transfer, Vol 50, Issues 13-14, July, 2643- 2655.

https://doi.org/10.1016/i.ijheatmasstransfer.2006.11.025

Joshi H., Hoeve F. and Zijden E. 2007. "Applying Technology Advancements to Improve Heat Exchanger Economic and Environmental Performance in Refinery Crude Preheat Trains," Proceedings on Heat Exchanger Fouling and Cleaning - Challenges and Opportunities, [2007], Vol. RP5, Article 7. [http://dc.engconfintl.org/cgi/viewcontent.cgi?article $=1007 \&$ context $=\mathrm{h}$ eatexchanger2007, accessed Nov. 21, 2017]

Joshi, H. M., Shilpi, N. B., and Agarwal, A. 2009. "Relate Crude Oil Fouling Research to Field Fouling Observations," Proc of International Conference on Heat Exchanger Fouling and Cleaning VIII - 2009 (Peerreviewed) June 14-19, 2009, Schladming, Austria

Joshi H.M. 2013. "Crude Oil Fouling Field Data and a Model for PilotPlant Scale Data," Proc. of International Conference on Heat Exchanger Fouling and Cleaning, June 09-14, 2013, Budapest, Hungary.

[http://www.heatexchanger-

fouling.com/papers/papers2013/04 Joshi F.pdf, accessed Nov. 22, 2017]

Kaneko H., Inasawa S., Inokuchi H., Funatsu K. 2009. "Construction of High Predictive Fouling Models Using Statistical Methods," Proc. of International Conference on Heat Exchanger Fouling and Cleaning VIII - June 14-19, 2009, Schladming, Austria.

https://doi.org/heatexhanger-fouling.com

Kazi, S. N., Duffy, G. G. 2 and Chen, X. D. 2009. "Fouling and Fouling Mitigation on Different Heat Exchanging Surfaces," Proceedings of International Conference on Heat Exchanger Fouling and Cleaning VIII - 2009 (Peer-reviewed) June 14-19, 2009, Schladming, Austria. [http://heatexchanger-fouling.com/papers/papers2009/52_Duffy_F.pdf, accessed Nov. 21, 217]

Kern, D.Q. and Seaton, R.E. 1959. "A Theoretical Analysis of Thermal Surface Fouling”, British Chemical Engineering, 4 (5), 258-262.

Klaren D. G. and De Boer E. F. 2007. '“Zero Fouling”' Self-Cleaning Heat Exchanger. Heat Transfer Engineering, 28(3):216-221.

http://dx.doi.org/10.1080/01457630601064645

Klaren D.G., de Boer E.F., and Sullivan D.W 2007. "Low Fouling Crude Oil Preheaters: Scrap Your Existing Conventional Crude Oil Preheaters, Replace Them by Low Fouling Heat Exchangers and Save Money. Proc. Heat Exchanger Fouling and Cleaning - Challenges and Opportunities. [2007], Vol. RP5, Article 32

Klaren, D. G., and Sullivan, D. W. 2001. "Improvements and Achievements in Self-Cleaning Heat Transfer, AIChE Process Innovation for Existing Processes, Houston.
Labbadlia, O., Laribi, B., Chetti, B. and Hendrick, P. 2017. "Numerical study of the influence of tube arrangement on the flow distribution in the header of shell and tube heat exchangers," Applied Thermal Engineering, 126315 - 321. http://dx.doi.org/10.1016/j.applthermaleng.2017.07.184

Lane, M.R. and Harris, J. S., 2015. "Impact of Mixing on Crude Oil Fouling Tests," Proc. of International Conference on Heat Exchanger Fouling and Cleaning - June 07 - 12, 2015, Enfield (Dublin), Ireland. [http://www.heatexchanger-fouling.com/papers/papers2015/03_Lane_ HTRI_F.pdf, accessed Nov. 21, 2017]

Lemos, J.C., Costa, A.L.H. and Bagajewicz, M.J. 2017. "Linear method for the design of shell and tube heat exchangers including fouling modeling," Applied Thermal Engineering, 1251345 - 1353. http://dx.doi.org/10.1016/j.applthermaleng.2017.07.066

Lestina, T. G and Zettler, H. 2014. "Crude Oil Fouling Research: HTRI's Perspective," Heat Transfer Engineering, 35(3):217-223, 2014. http://dx.doi.org/10.1080/01457632.2013.825153

Liporace, F. S. and Oliveira, S. G. 2005. "Real Time Fouling Diagnosis and Heat Exchanger Performance," Proc. of 6th International Conference on Heat Exchanger Fouling and Cleaning - Challenges and Opportunities, Vol RP2, Article 39. [http://dc.engconfintl.org/cgi/viewcontent.cgi?article $=1034 \&$ context $=\mathrm{h}$ eatexchanger2005, accessed Nov. 21, 2017]

Liporace, F. S., and Oliveira, S. G. 2007. "Real Time Fouling Diagnosis and Heat Exchanger Performance," Heat Transfer Engineering, Vol. 28, 193-201. https://doi.org/10.1080/01457630601064595

Macchietto, S., Hewitt, G.F., Coletti, F., Crittenden, B.D., Dugwell, D.R., Galind, A., Jackson, G., Kandiyoti, R., Kazarian, S.G. 1, Luckham, P.F., Matar, O.K., Millan-Agorio, M., Müller, E.A., Paterson, W., Pugh, S.J., Richardson, S.M. and Wilson, D.I. 2009. "Fouling in Crude Oil Preheat Trains: A Systematic Solution to an Old Problem," Procs of International Conference on Heat Exchanger Fouling and Cleaning VIII - 2009 (Peer-reviewed) June 14-19, 2009, Schladming, Austria https://doi.org/10.1080/01457632.2010.495579

Master, B. I., Chunangad, K. S. and Pushpanathan, V. 2003. "Fouling Mitigation Using Helixchanger Heat Exchangers," Proceedings Heat Exchanger Fouling and Cleaning: Fundamentals and Applications Engineering Conferences International- 2003. [http://citeseerx.ist.psu.edu/viewdoc/download?doi=10.1.1.905.4404\&r ep=rep1\&type=pdf, accessed Nov. 21, 2017]

Mercère G., Pálsson H., and Poinot T. 2013. "Linear Parameter Varying Identification of a Cross Flow Heat Exchanger for Fouling Detection," 6th Workshop on Fractional Differentiation and its Applications (IFAC Joint Conference FDA), 2013. [http://heatexchangerfouling.com/papers/papers2009/62_Mercere_F.pdf, accessed Nov. 21, 2017]

Morimoto N., Nakamura M., Yamane Y. and Inokuchi H. 2011. "Development of a Conceptual Model of Crystallization in a Heat Exchanger," Proc. of International Conference on Heat Exchanger Fouling and Cleaning - June 05 - 10, 2011, Crete Island, Greece. [http://www.heatexchanger-

fouling.com/papers/papers2011/40_Morimoto_F.pdf, accessed Nov. 21, 2017]

Müller-Steinhagen, H. 2000. Heat Exchanger Fouling - Mitigation and Cleaning Technologies. IChemE, Rugby, Warwickshire, UK 
Müller-Steinhagen, H., Malayeiri, M. R., and Watkinson, A. P. 2009. "Heat Exchanger Fouling: Environmental Impacts," Heat Transfer. Engineering, 30, 773-776.

https://doi.org/10.1080/01457630902744119

Müller-Steinhagen, H., Malayeri, M. R and Watkinson, A. P. 2011. Heat Exchanger Fouling and Cleaning. Heat Transfer Engineering, 28 (3)173-176.

http://dx.doi.org/10.1080/01457632.2013.737751

Müller-Steinhagen, H. and Malayeri M. R. 2007. Recent Advances in Heat Exchanger Fouling Research, Mitigation, and Cleaning Techniques. Heat Transfer Engineering, 28(3),173-176.

https://doi.org/10.1080/01457630601064397

Murphy, G., and Campbell, J., 1992. "Fouling in Refinery Heat Exchangers in M. Bohnet et al. (eds.), Fouling Mechanisms, 249-261, GRETh Seminar, Grenoble, France.

Nasr, M. R. J., and Givi, M. M., 2006. "Modeling of crude oil fouling in preheat exchangers of refinery distillation units", Appl. Therm. Eng., 26, $1572-1577$.

https://doi.org/10.1016/j.applthermaleng.2005.12.001

Nesta J. and Bennett C.A. 2004. "Reduce Fouling in Shell-And Tube Heat Exchangers," Journal of Hydrocarbon Processing, 2004, 83(7), 77 $-82$

Nesta, J. and Bennett, C. A. 2005. "Fouling Mitigation by Design," Heat Exchanger Fouling and Cleaning - Challenges and Opportunities 2005, Vol. RP2, Article 49.

http://dc.engconfintl.org/cgi/viewcontent.cgi?article=1048\&context=he atexchanger2005, accessed Nov. 21, 2017]

Panchal, C. B., Kuru, W. C., Liao, C. F., and Ebert, W. A., 1999. "Threshold conditions of crude oil fouling," Understanding Heat Exchanger Fouling and Mitigation, Begell House, New York.

Polley, G.T. and Gonzales-Garcia G. 2009. "Procedure for Applying Fouling Models to Predict Overall Fouling Rates in Industrial Heat Exchangers," Proc. of 7th International Conference on Heat Exchanger Fouling and Cleaning - Challenges and Opportunities, June 14-19, 2009, Schladming, Austria

Polley, G.T., Morales Fuentes A. and Wilson, D.I. 2007. "Simultaneous Consideration of Flow and Thermal Effects of Fouling in Crude Oil Preheat Trains," Proceedings of 7th International Conference on Heat Exchanger Fouling and Cleaning - Challenges and Opportunities, Tomar, Portugal, July 1 - 6, 2007

Polley G.T., Morales A. F. and Pugh S.J. 2009. "Design of Shell-andTube Heat Exchangers to Achieve a Specified Operating Period in Refinery Pre-Heat Trains," Proc. of International Conference on Heat Exchanger Fouling and Cleaning VIII - 2009 June 14-19, Schladming, Austria. https://doi.org/10.1080/01457632.2010.495655

Polley G.T., Wilson D.I., Pugh S.J. and Petitjean E. 2007. Extraction of Crude Oil Fouling Model Parameters from Plant Exchanger Monitoring", Heat Transfer Engineering., 28(3), 185-192.

[http://dc.engconfintl.org/cgi/viewcontent.cgi?article $=1001 \&$ context $=\mathrm{h}$ eatexchanger2005, accessed Nov. 21, 2017]

Polley, G. T., Wilson, D. I. and Pugh, S., 2000. "Designing Crude Oil Pre-Heat Trains with Fouling Mitigation," Proc. 3rd International Conference on Refining Procedures, AICHE: New York, 519-523.
Polley, G.T., Wilson, D.I., Pugh, S.J. and Petitjean, E. 2005. "Extraction of Crude Oil Fouling Model Parameters from Plant Exchanger Monitoring Fouling Detection in A Cross-Flow Heat Exchanger Based on Physical Modeling," Heat Exchanger Fouling and Cleaning Challenges and Opportunities -2005, Vol. RP2, Article 5.

[http://dc.engconfintl.org/heatexchanger2005/5, accessed Nov. 21, 2017]

Polley, G. T., Wilson, D. I., Yeap, B. L., and Pugh, S. J., 2002, "Evaluation of laboratory crude oil threshold fouling data for application to refinery pre-heat trains", Appl. Therm. Eng., 22, 777-788. https://doi.org/10.1016/S1359-4311(02)00023-6

Ratel, M., Kapoor, Y., Anxionnaz-Minvielle, Z., Seminel, L. and Vinet, B. 2013. "Investigation of Fouling Rates in a Heat Exchanger Using an Innovative Fouling Rig," Proceedings of International Conference on Heat Exchanger Fouling and Cleaning - 2013 (Peer-reviewed) June 09 - 14, 2013, Budapest, Hungary

Riverol C. and Napolitano V. 2005. "Estimation of Fouling in a Plate Heat Exchanger Through the Application of Neural Networks," Journal of Chemical Technology and Biotechnology, 80,594-600. doi: $10.1002 /$ jctb. 1198

Rodriguez C. and Smith R. (2007). "Optimization of Operating Conditions for Mitigating Fouling in Heat Exchanger Networks," Chemical Engineering Research and Design, 85(A6), 839-851. https://doi.org/10.1205/cherd06046

Saleh, Z., Sheikholeslami, R. and Watkinson, A.P., 2003. "Fouling characteristics of a light Australian crude oil," Proc. of Heat Exchanger Fouling and Cleaning: Fundamentals and Applications, 226-233, Santa Fe, NM.

[http://dc.engconfintl.org/cgi/viewcontent.cgi?article $=1030 \&$ context $=h$ eatexchanger, accessed Nov. 21, 20177]

Saleh Z. S., Sheikholeslami R. and. Watkinson A. P. 2005. "Blending Effects on Fouling of Four Crude Oils," Proc. on Heat Exchanger Fouling and Cleaning - Challenges and Opportunities, 2005, Vol. RP2, Article 7. [http://dc.engconfintl.org/heatexchanger2005/7, accessed Nov. 21, 2017]

Shetty, N., Deshannavar, U. B., Marappagounder, R., Pendyala R., 2016. "Improved Threshold Fouling Models for Crude Oils," Energy 111 (2016), 453-467.

https://doi.org/10.1016/j.energy.2016.05.130

Sileri D., Sahu K., Ding H. and Matar O.K. 2009. "Mathematical Modelling of Asphaltenes Deposition and Removal in Crude Distillation Units," Proc. of International Conference on Heat Exchanger Fouling and Cleaning VIII - June 14-19, 2009, Schladming, Austria

Srinivasan, M. and Watkinson, A.P. 2003. "Fouling of Some Canadian Crude Oils," Proceedings Heat Exchanger Fouling and Cleaning: Fundamentals and Applications. Engineering Conferences International $-2003$

Srinivasan, M. and Watkinson, A.P. 2006. "Fouling of some Canadian crude oils", Heat Transfer Eng., Vol. 26 (1),7-14.

https://doi.org/10.1080/01457630590889988

Wilson D. I. 2003. "Challenges in Cleaning: Recent Developments and FuturProspects," Proc of Heat Exchanger Fouling and Cleaning: Fundamentals and Applications, Engineering Conferences International. Art. 212003.

[http://citeseerx.ist.psu.edu/viewdoc/download?doi=10.1.1.474.7510\&r ep=rep1\&type =pdf, accessed Nov. 21, 2017] 
Wilson D.I., Polley, G.T., and Pugh S.J. 2005. "Ten years of Ebert, Panchal and the 'Threshold Fouling' Concept," Proc. of Heat Exchanger Fouling and Cleaning - Challenges and Opportunities -2005, Vol. RP2, Article 6.

[http://dc.engconfintl.org/cgi/viewcontent.cgi?article $=1002 \&$ context $=h$ eatexchanger2005, accessed Nov. 21, 2017]

Watkinson A. P. 2003. "Comparison of Crude Oil Fouling Using Two Different Probes," Proc. on Heat Exchanger Fouling and Cleaning Fundamentals and Applications. Engineering Conferences International. Art. 322003.

[http://dc.engconfintl.org/cgi/viewcontent.cgi?article $=1031 \&$ context $=\mathrm{h}$ eatexchanger, accessed Nov. 22, 2017]

Wen, X., Miao, Q., Wang, J. and Ju, Z. 2017. “A multi-resolution wavelet neural network approach for fouling resistance forecasting of a plate heat exchanger," Applied Soft Computing, 57177 - 196.

http://dx.doi.org/10.1016/j.asoc.2017.03.043
Yang M., O’Meara A. and Crittenden B. D. 2011. "Determination of Crude Oil Fouling Thresholds," Proc. of International Conference on Heat Exchanger Fouling and Cleaning - June 05 - 10, 2011, Crete Island, Greece.

Yang, M., Young, A., Niyetkaliyev, A. and Crittenden, B. 2009. "Modelling the Fouling Induction Period," Proceedings of International Conference on Heat Exchanger Fouling and Cleaning VIII - 2009, June 14-19, 2009, Schladming, Austria. [http://www.heatexchangerfouling.com/papers/papers2009/10_Crittenden_Induction_F.pdf, accessed Nov. 21, 2017]

Yunus, C.A. and Afshin, G. J. 2015. "Heat and Mass Transfer: Fundamentals \& Applications", 5th Edition, McGraw-Hill, New York 